\section{HEARING AND NOISE IN} AVIATION

\section{HEARING}

$\mathrm{T}$

he term hearing describes the process, function, or power of perceiving sound. Hearing is second only to vision as a physiological sensory mechanism to obtain critical information during the operation of an aircraft. The sense of hearing makes it possible to perceive, process, and identify among the myriad of sounds from the surrounding environment.

\section{Anatomy and Physiology of the Auditory System}

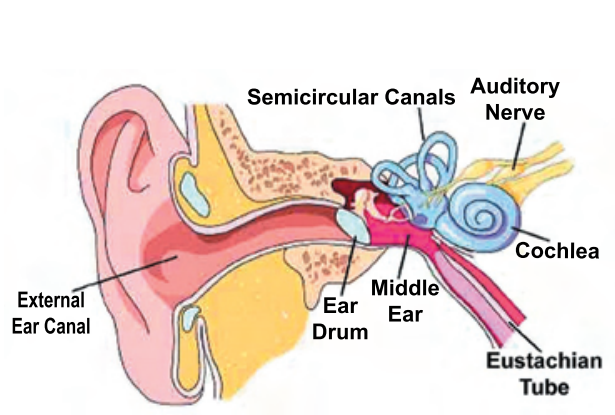

The auditory

system consists of the external ear, ear canal, eardrum, auditory ossicles, cochlea (which resembles a

snail shell and is filled with fluid), and the auditory nerve.

Ambient sound waves are collected by the external ear, conducted through the ear canal, and cause the eardrum to vibrate. Eardrum vibration is mechanically transmitted to the ossicles, which, in turn, produce vibration of a flexible window in the cochlea. This vibration causes a pressure wave in the fluid located inside the cochlea, moving thousands of hair-like sensory receptors lining the inner walls of the cochlea. The movement of these receptors resembles the gentle movement of a crop field caused by the wind. The stimulation of these sensors produces an electrical signal that is transmitted to the brain by the auditory nerve. This signal is then processed by the brain and identified as a particular type of sound.

\section{SOUND}

The term sound is used to describe the mechanical radiant energy that is transmitted by longitudinal pressure waves in a medium (solid, liquid, or gas). Sound waves are variations in air pressures above and below the ambient pressure. From a more practical point of view, this term describes the sensation perceived by the sense of hearing. All sounds have three distinctive variables: frequency, intensity, and duration.

Frequency. This is the physical property of sound that gives it a pitch. Since sound energy propagates in a wave-form, it can be measured in terms of wave oscillations or wave cycles per second, known as hertz $(\mathrm{Hz})$. Sounds that are audible to the human ear fall in the frequency range of about 20-20,000 $\mathrm{Hz}$, and the highest sensitivity is between 500 and $4,000 \mathrm{~Hz}$. Sounds below $20 \mathrm{~Hz}$ and above 20,000 $\mathrm{Hz}$ cannot be perceived by the human ear. Normal conversation takes place in the frequency range from 500 to $3,000 \mathrm{~Hz}$.

Intensity. The correlation between sound intensity and loudness. The decibel $(\mathrm{dB})$ is the unit used to measure sound intensity. The range of normal hearing sensitivity of the human ear is between -10 to $+25 \mathrm{~dB}$. Sounds below $-10 \mathrm{~dB}$ are generally imperceptible. A pilot who cannot hear a sound unless its intensity is higher than $25 \mathrm{~dB}$ (at any frequency) is already experiencing hearing loss.

Duration. Determines the quality of the perception and discrimination of a sound, as well as the potential risk of hearing impairment when exposed to high intensity sounds. The adverse consequences of a short-duration exposure to a loud sound can be as bad as a long-duration exposure to a less intense sound. Therefore, the potential for causing hearing damage is determined not only by the duration of a sound but also by its intensity.

\section{NOISE}

The term noise refers to a sound, especially one which lacks agreeable musical quality, is noticeably unpleasant, or is too loud. In other words, noise is 
any unwanted or annoying sound. Categorizing a sound as noise can be very subjective. For example, loud rock music can be described as an enjoyable sound by some (usually teenagers), and at the same time described as noise by others (usually adults).

Sources of Noise in Aviation. The aviation environment is characterized by multiple sources of noise, both on the ground and in the air. Exposure of pilots to noise became an issue following the introduction of the first powered aircraft by the Wright Brothers, and has been a prevalent problem ever since. Noise is produced by aircraft equipment powerplants, transmission systems, jet efflux, propellers, rotors, hydraulic and electrical actuators, cabin conditioning and pressurization systems, cockpit advisory and alert systems, communications equipment, etc. Noise can also be caused by the aerodynamic interaction between ambient air (boundary layer) and the surface of the aircraft fuselage, wings, control surfaces, and landing gear. These auditory inputs allow pilots to assess and monitor the operational status of their aircraft. All pilots know the sounds of a normal-functioning aircraft. On the other hand, unexpected sounds or the lack of them, may alert pilots to possible malfunctions, failures, or hazards. Every pilot has experienced a cockpit or cabin environment that was so loud that it was necessary to shout to be heard. These sounds not only make the work environment more stressful but can, over time, cause permanent hearing impairment. However, it is also important to remember that individual exposure to noise is a common occurrence away from the aviation working environment-at home or work, on the road, and in public areas. The effects of pre-flight exposure to noise can adversely affect pilot in-flight performance.

\section{Sources of Sound/Noise}

\begin{tabular}{|l|c|}
\hline SOURCES & LEVEL (dB) \\
\hline Whispered Voice & $20-30$ \\
\hline Urban Home, Average Office & $40-60$ \\
\hline Average Male Conversation & $60-65$ \\
\hline Noisy Office, Low Traffic Street & $60-80$ \\
\hline Jet Transports (Cabin) & $60-88$ \\
\hline Small Single Plane (Cockpit) & $70-90$ \\
\hline Public Address (PA) Systems & $90-100$ \\
\hline Busy City Street & $80-100$ \\
\hline Single Rotor Helicopter (Cockpit) & $80-102$ \\
\hline Power Lawn Mower, Chain Saw & $100-110$ \\
\hline Snowmobile, Thunder & $110-120$ \\
\hline Rock Concert & $115-120$ \\
\hline Jet Engine (Proximity) & $130-160$ \\
\hline
\end{tabular}

\section{Types of Noise}

Steady: Continuous noise of sudden or gradual onset and long duration (more than 1 second). Examples: aircraft powerplant noise, propeller noise, and pressurization system noise. According to the Occupational Safety and Health Administration (OSHA), the maximum permissible continuous exposure level to steady noise in a working environment is $90 \mathrm{~dB}$ for 8 hours.

Impulse/blast: Noise pulses of sudden onset and brief duration (less than 1 second) that usually exceed an intensity of $140 \mathrm{~dB}$. Examples: firing a handgun, detonating a firecracker, backfiring of a piston engine, high-volume squelching of radio equipment, and a sonic boom caused by breaking the sound barrier. The eardrum may be ruptured by intense levels $(140 \mathrm{~dB})$ of impulse/blast noise.

\section{EFFECTS OF NOISE EXPOSURE}

\section{Physiologic}

- Ear discomfort: May occur during exposure to a $120 \mathrm{~dB}$ noise.

- Ear pain: May occur during exposure to a $130 \mathrm{~dB}$ noise.

- Eardrum rupture: May occur during exposure to a $140 \mathrm{~dB}$ ) noise.

- Temporary hearing impairment. Unprotected exposure to loud, steady noise over $90 \mathrm{~dB}$ for a short time, even several hours, may cause hearing impairment. This effect is usually temporary and hearing returns to normal within several hours following cessation of the noise exposure.

- Permanent hearing impairment: Unprotected exposure to loud noise (higher than $90 \mathrm{~dB}$ ) for eight or more hours per day for several years, may cause a permanent hearing loss. Permanent hearing impairment occurs initially in the vicinity of $4,000 \mathrm{~Hz}$ (outside the conversational range) and can go unnoticed by the individual for some time. It is also important to remember that hearing sensitivity normally decreases as a function of age at frequencies from 1,000 to $6,000 \mathrm{~Hz}$, beginning around age 30 . 


\section{Psychologic}

- Subjective effects: Annoying high-intensity noise can cause distraction, fatigue, irritability, startle responses, sudden awakening and poor sleep quality, loss of appetite, headache, vertigo, nausea, and impair concentration and memory.

- Speech interference: Loud noise can interfere with or mask normal speech, making it difficult to understand.

- Performance: Noise is a distraction and can increase the number of errors in any given task. Tasks that require vigilance, concentration, calculations, and making judgments about time can be adversely affected by exposure to loud noise higher than $90 \mathrm{~dB}$.

\section{HOW TO PROTECT YOUR HEARING}

Limiting duration of exposure to noise. OSHAestablished permissible noise exposure limits for the workplace (including the cockpit of an aircraft):

\section{Noise Exposure Level Limits}

\begin{tabular}{|c|c|}
\hline $\begin{array}{c}\text { Noise Intensity } \\
\text { (dB) }\end{array}$ & $\begin{array}{c}\text { Exposure Limit } \\
\text { (hrs. per day) }\end{array}$ \\
\hline 90 & 8 \\
\hline 92 & 6 \\
\hline 95 & 4 \\
\hline 97 & 3 \\
\hline 100 & 2 \\
\hline 102 & 1.5 \\
\hline 105 & 1 \\
\hline 110 & .5 \\
\hline 115 & .25 \\
\hline
\end{tabular}

Use Hearing Protection Equipment. If the ambient noise level exceeds OSHA's permissible noise exposure limits, you should use hearing protection devices-earplugs, earmuffs, communication headsets, or active noise reduction headsets. Even if an individual already has some level of permanent hearing loss, using hearing protection equipment should prevent further hearing damage. These protection devices attenuate noise waves before they reach the eardrum, and most of them are effective at reducing high-frequency noise levels above $1,000 \mathrm{~Hz}$. It is very important to emphasize that the use of these devices does not interfere with speech communications during flight because they reduce high-frequency background noise, making speech signals clearer and more comprehensible.
- Earplugs. Insertable-type earplugs offer a very popular, inexpensive, effective, and comfortable approach to provide hearing protection. To be effective, earplugs must be inserted properly to create an air-tight seal in the ear canal. The waximpregnated moldable polyurethane earplugs provide an effective universal fit for all users and provide 30 to $35 \mathrm{~dB}$ of noise protection across all frequency bands.

- Communication headsets. In general, headsets provide the same level of noise attenuation as earmuffs, and are also more easily donned and removed that earplugs, but the microphone can interfere with the donning of an oxygen mask.

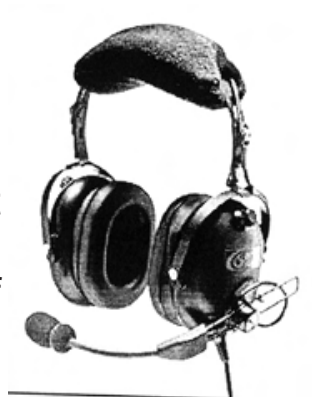

- Active noise reduction headsets. This type of headset uses active noise reduction technology that allows the manipulation of sound and signal waves to reduce noise, improve signal-to-noise ratios, and enhance sound quality. Active noise reduction provides effective protection against lowfrequency noise. The electronic coupling of a lowfrequency noise wave with its exact mirror image cancels this noise.

- Combinations of protection devices. The combination of earplugs with earmuffs or communication headsets is recommended when ambient noise levels are above $115 \mathrm{~dB}$. Earplugs, combined with active noise reduction headsets, provide the maximum level of individual hearing protection that can be achieved with current technology.

\section{SUMMARY}

- Hearing is second only to vision as a sensory mechanism to obtain critical information during the operation of an aircraft.

- All sounds have three distinctive variables: frequency, intensity, and duration.

- Normal conversation takes place in the frequency range from 500 to $3,000 \mathrm{~Hz}$.

- Daily exposure to noise levels higher than $90 \mathrm{~dB}$ can cause hearing impairment. This can go unnoticed initially because it occurs in the vicinity of $4,000 \mathrm{~Hz}$ (outside the conversational range)

- If the ambient noise level reaches 90dBA, you 
must use hearing protection equipment to prevent hearing impairment.

- Exposure to loud noise before flying (at home, while driving, at a party, etc.) can be as harmful as exposure to aircraft noise.

\section{MEDICAL FACTS FOR PILOTS}

Publication: AM-400-98/3

Written by: Melchor J. Antuñano, M.D., and James P. Spanyers

Prepared by: FAA Civil Aerospace Medical Institute Aeromedical Education Division

AAM-400, P.O. Box 25082

Oklahoma City, OK 73125

\section{Other Pilot Safety Brochures Available}

Number Title

AM-400-94/2 Alcohol and Flying: A Deadly Combination

OK05-0270 Carbon Monoxide: A Deadly Threat

AM-400-03/2 Deep Vein Thrombosis and Travel

AM-400-91/1 Hypoxia: The Higher You Fly, the Less Air...

AM-400-97/1 Introduction to Human Factors in Aviation

AM-400-92/1 Over the Counter Medications and Flying

AM-400-98/2 Pilot Vision

AM-400-95/1 Smoke!

AM-400-00/1 Spatial Disorientation: Visual Illusions

AM-400-03/1 Spatial Disorientation: Why You Shouldn't Fly By the Seat of Your Pants

AM-400-01/1 Physiological Training Courses for Civil Aviation Pilots

AM-400-05/1 Sunglasses for Pilots: Beyond the Image

To view these pilot and passenger safety brochures, visit the Federal Aviation Administration's Web Site:

www.faa.gov/pilots/safety

\section{Physiological Training Classes for} Pilots

If you are interested in taking a one-day aviation physiological training course with altitude chamber and vertigo demonstrations or a one-day survival course, learn about these courses by visiting this FAA Web site:

www.faa.gov/pilots/training/airman_education 